\title{
Fast and simple selenium speciation by solid phase extraction and laser-induced breakdown spectroscopy
}

\author{
Seon Hwa Lee, Seul-Woo Kwon, Yonghoon Lee and Sang-Ho Nam ${ }^{*}$ (D)
}

\begin{abstract}
The chemical properties including toxicity of selenium depend on the concentration and chemical structure present in the natural environment. Inorganic selenium is more toxic than organic selenium; thus, the accurate determination of inorganic selenium in various sample has been needed. HG-AAS, HPLC-ICP-MS, and GC-MS are the current methods for the determination of inorganic selenium. However, these methods have the disadvantage of expensive equipment, complicated sample preparation, and long analysis time. LIBS coupled with ion exchange membrane was used for the determination of inorganic selenium. The detection limit of inorganic selenium by the analytical method was 11.21 $\mathrm{mg} / \mathrm{kg}$, and the recoveries of 50 and $100 \mathrm{mg} / \mathrm{kg} \mathrm{Se}(\mathrm{Vl})$ were $98.5 \%$ and $101.80 \%$, respectively. The speciation method is cost-effective, simple, and not labor intensive for the quantitation of inorganic selenium.
\end{abstract}

Keywords: Selenium, Inorganic selenium, Toxicity, LIBS, lon exchange membrane, Speciation

\section{Introduction}

Selenium is known to be an essential trace element in terms of antioxidant activity, but it exhibits toxicity at high concentrations (Lobinski et al. 2000). Selenium is widely used not only in photography, pharmaceutical production, and rubber vulcanization but also in the fields of ceramics, glass, photovoltaics, pigments, rectifier semiconductors, and steel (Foster and Sumar 1997). However, there is a very narrow range of difference between beneficial and harmful levels of health. Daily selenium intake less than $0.1 \mathrm{mg}$ per $1 \mathrm{~kg}$ of body causes selenium deficiency. However, the daily ingestion of selenium exceeding $1 \mathrm{mg}$ per $1 \mathrm{~kg}$ of body can be toxic to an average person (Suzuki et al. 1995). The diseases caused by selenium deficiency were cardiovascular disease, impaired immune function, aging promotion, etc. (Alissa et al. 2003). Poisoning symptoms are a typical metallic taste in the mouth, severe irritation in the respiratory system, pulmonary edema, and garlic-specific

\footnotetext{
* Correspondence: shnam@mokpo.ac.kr

Department of Chemistry, Mokpo National University, 61 Dorim-ri, Chungkye-myon, Muan-gun, Chonnam 58554, Republic of Korea
}

odors from respiration and sweat (Navarro-Alarcón and López-Martínez 2000). The recommended intake of selenium by the World Health Organization was 30 to 40 mg per day for adult men and women (Trace elements in human nutrition and health. World Health Organ (WHO) 1996).

In general, the main route through which people are exposed to selenium is food, followed by water and air (Selinus 2013). The selenium content of food produced from the soil is highly dependent on the amount of selenium present in the soil. Selenium concentrations in soils around the world are generally varied between 0.01 and $1000 \mathrm{mg} / \mathrm{kg}$ (Thomson 2004). The amount of selenium present in the soil varied depending on the country and region, and the amount of selenium in a plant varied depending on the ability of plants to absorb and accumulate selenium (Dumont et al. 2006). We intake most selenium from bread, cereal, meat, and poultry. Selenium concentrations are lower in animal foods than in vegetable foods (Mahima et al. 2012). Plants preferentially absorb selenate and convert it to selenium organic compounds (Finley 2005). In the case of aquatic 
organisms, selenium can be accumulated and expanded through the food chain (Sandholm et al. 1973). Selenium is abundant in fish viscera and meat, but the utilization rate of selenium in the body is the largest by selenium rich cereals and grains. Dairy products, fruits, and vegetables have the lowest selenium content (Brown and Arthur 2001).

The four natural oxidation states of selenium are elemental selenium, selenide $\left(\mathrm{Se}^{2-}\right)$, selenite $\left(\mathrm{Se}^{4+}\right)$, and selenate $\left(\mathrm{Se}^{6+}\right)$ (Fio and Fujii 1990). Organic selenium compounds are the major selenium species in grains and vegetables, while inorganic selenium is abundant in water (Xiong et al. 2018). Inorganic selenium species such as Se (VI) and Se (IV) are more toxic than organic selenium such as dimethyl selenide, dimethyl diselenide, trimethyl selenonium ion, Se-cystine (Se-Cys), selenourea, selenobetaine, and Se-methionine (Se-Met) (Rohn et al. 2018). Many studies showed that selenium existed in various forms of inorganic and organic compounds in living organisms and foods, and its toxicity varied depending on the chemical species (Garousi 2015). Thus, it is difficult to evaluate the exact toxicity only by total amount of selenium in a sample. Accordingly, it is very important and meaningful to separate and quantify the different selenium species rather than analyzing the total selenium in the various samples.

In the last decade, the most work for selenium speciation has been done by the chromatographic method for separation of the selenium species using IC-ICP-MS, HPLC-ICP-MS, and ESI-MS for the detection of the separated selenium species (Michalke 2003; Roberge et al.
2003; Li et al. 2010). The method has been universally used because it was very sensitive and accurate. LIBS has been used for chromium and arsenic speciation after the elemental species were separated by ion exchange membrane (Dockery et al. 2005; Nam et al. 2018). LIBS has several advantage in terms of the simple sample preparation, fast analysis time, and cost advantages.

In this study, the LIBS coupled with ion exchange membrane was used for the determination of inorganic selenium. The solid phase extraction (SPE) membrane was used to separate inorganic selenium, and those were detected by laser-induced breakdown spectroscopy (LIBS). A syringe-type SPE membrane filter has been widely used to remove the impurities in the sample solution for the sample preparation. However, in our study, the inorganic selenium retained on the disk was directly analyzed by LIBS. The $\mathrm{pH}$ value of the sample was adjusted to 4 using ammonium hydroxide and phosphoric acid for the efficient separation of inorganic selenium species. The recovery efficiency of Se (VI) by LIBS was $100.2 \%$. From the results, it was confirmed that inorganic selenium species could be separated and detected using SPE membrane and LIBS.

\section{Methods}

\section{lon exchange membrane}

Inorganic selenium (Se (VI)) can be separated using ion exchange membranes as anionic form at $\mathrm{pH} 7$. Anion exchange was performed on $47-\mathrm{mm}$ round segments of a solid phase extraction disk Empore $^{\mathrm{TM}}, 3 \mathrm{M}$ Corp, St. Paul, MN). The anion exchange polymer has a polymer

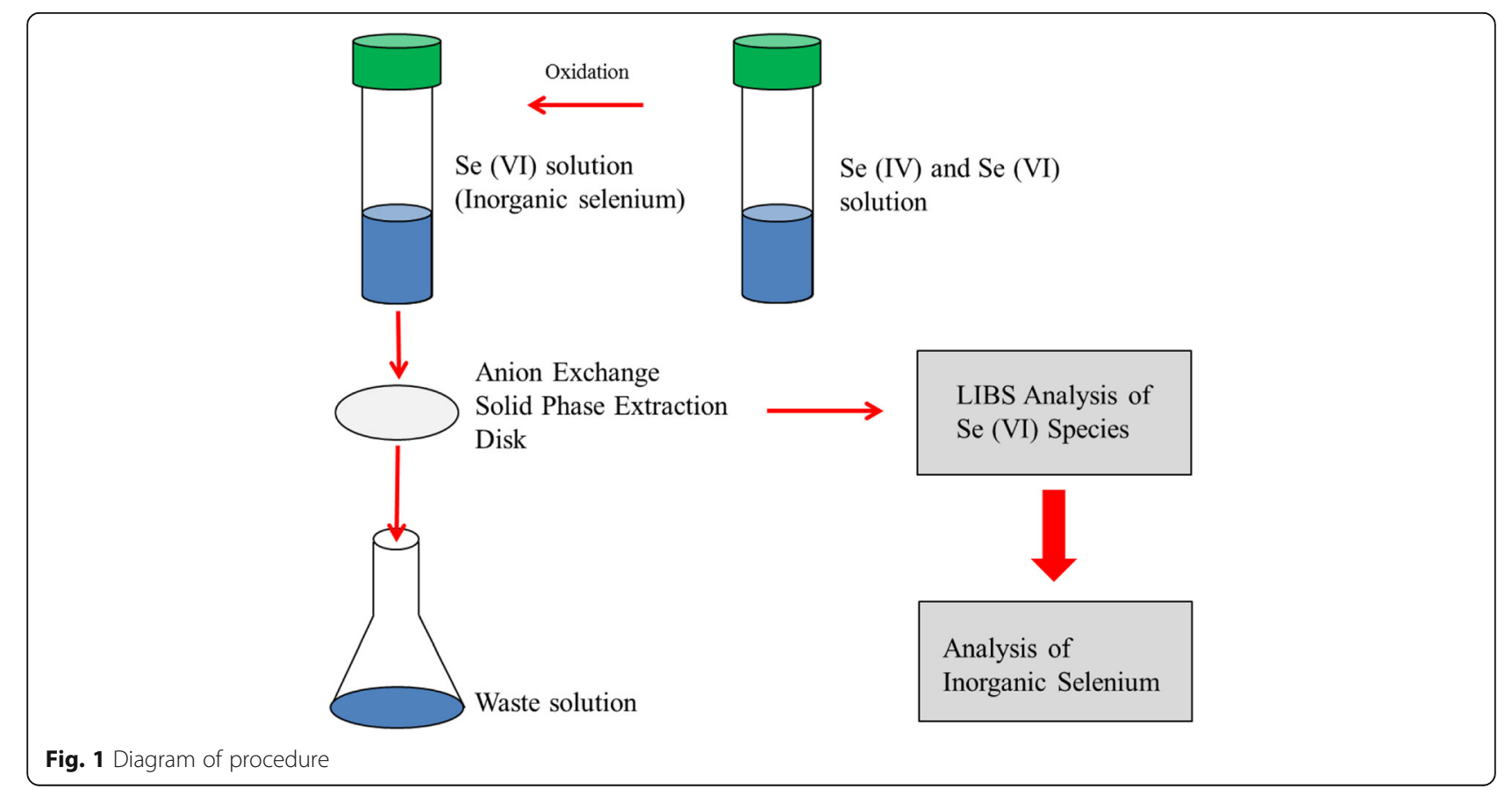


support functionalized by trimethyl ammonium propyl group. Filtration was performed using a locally glass funnel with a diameter of $47 \mathrm{~mm}$. The membrane was conditioned according to the manufacturer's instruction that was described in procedure in detail. The standards were directly filtered without any pretreatment. Since the samples were prepared from Se (IV) and Se (VI), Se (IV) was oxidized to Se (VI) and passed through the membrane. Then, the membranes were dried in the oven, of which temperature was $40^{\circ} \mathrm{C}$, for about $24 \mathrm{~h}$ and analyzed by LIBS.

\section{Apparatus}

The commercial LIBS instrument (RT100-EC, Applied Spectra, Inc.) was used with a Q-switched Nd:YAG laser $(1064 \mathrm{~nm}, 7 \mathrm{~ns}$, maximum $50 \mathrm{~mJ} /$ pulse, Polaris, New Wave Research) and a gateable 5-channel chargecoupled device (CCD) spectrometer (190-800 nm wavelength coverage, $\sim 0.1 \mathrm{~nm}$ resolution) for recording the LIBS spectra. The laser beam was focused on the substrate surface through an objective lens ( $\times 5$ magnification, $35 \mathrm{~mm}$ working distance). The calibration curve was obtained by focusing $10-\mathrm{mJ}$ laser pulse energy on the substrate surface. The plasma emission was collected through two lenses and sent to the spectrometer via an optical fiber bundle. The CCD detection gate with a $1.05-\mathrm{ms}$ width was delayed from the Q-switching event of the laser by $500 \mathrm{~ns}$ to optimize the signal-tobackground ratio. The laser was operated at the repetition rate of $10 \mathrm{~Hz}$. The laser beam spot size was set to $150 \mu \mathrm{m}$ in diameter on the sample surface. To record a single LIBS spectrum, signals from 1000 laser shot were accumulated. During the measurement, the sample stage was translated at the rate of $1 \mathrm{~mm} / \mathrm{s}$.

\section{Chemicals and reagents}

Stock solutions of Se (VI) were prepared by sodium selenate ( $\geq 95 \%$, Sigma-Aldrich Co.), and Se (IV) were prepared by sodium selenite (98\%, Sigma-Aldrich Co.) by using distilled deionized water as a solvent. The concentration of Se in each stock solution was set to $1000 \mathrm{mg} /$ $\mathrm{kg}$. The stock solutions were kept in the refrigerator of which temperature was set to $2{ }^{\circ} \mathrm{C}$. Calibration standards and samples were prepared by using distilled deionized water from the stock and ammonium hydroxide $(\geq 28 \%$, Sigma-Aldrich), and phosphoric acid (85-90\%, SigmaAldrich) was used to adjust pH (Martínez-Bravo et al. 2001). Hydrogen peroxide $(35 \%, 1 \mathrm{~mL})$ was used to oxidize Se (IV) to Se (VI).

\section{Procedure}

The membranes need to be conditioned before they are used. Acetone $(10 \mathrm{~mL})$, methanol $(10 \mathrm{~mL})$, distilled deionized water $(10 \mathrm{~mL})$, aqueous solution of sodium hydroxide
$(1 \mathrm{M}, 10 \mathrm{~mL})$, and distilled deionized water $(10 \mathrm{~mL})$ were flowed subsequently through them for their conditioning. Inorganic selenium solutions were filtered through the conditioned extraction membrane filter disk $(\sim 2 \mathrm{~mL} / \mathrm{min})$ by suction using a hand vacuum pressure pump. The volume of each solution was set to $10 \mathrm{~mL}$. After the filtration, Se (VI) was retained on the extraction membrane filter disk as it was shown in Fig. 1.

\section{Results and discussion}

\section{Optimum $\mathrm{pH}$ and flow rate}

The $\mathrm{p} K_{\mathrm{a}}$ values of Se (VI) and Se (IV) are 2.70 and 2.01, respectively (Peng et al. 2015; Wu and Sun 2016). Ionic characteristics of Se (IV) and Se (VI) highly depend on the $\mathrm{pH}$ of the solution. In order to separate Se (IV) and Se (VI) using ion exchange membrane, the two inorganic selenium species must exist in different forms such as neutral and ionic forms. But, in order to separate two

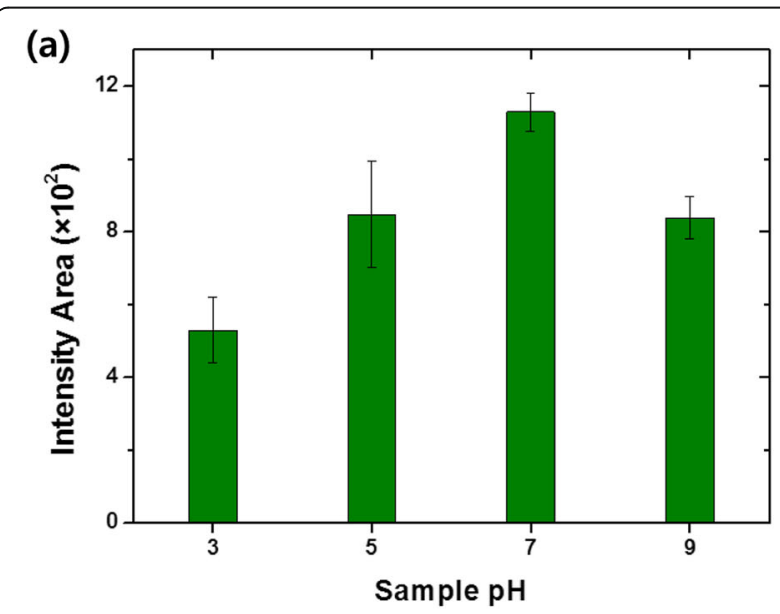

(b)

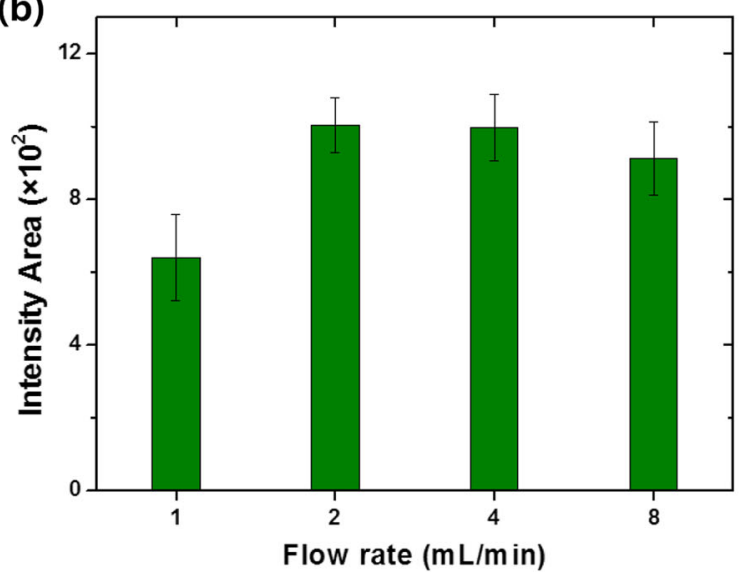

Fig. 2 The signal intensity of Se (VI) from LIBS spectra. a Signal intensities of Se (VI) at different $\mathrm{pH}$ values (3.0, 5.0, 7.0, and 9.0) and b those at different flow rates $(1.0,2.0,4.0$, and $8.0 \mathrm{~mL} / \mathrm{min})$. A $10-\mathrm{mL}$ solution was used for each analysis 
Table 1 Determination of Se $(\mathrm{VI})$ in $\mathrm{pH} 7$

\begin{tabular}{llll}
\hline Sample & Concentration of Se $(\mathrm{VI})$ in sample solution $(\mathrm{mg} / \mathrm{kg})$ & Result by LIBS $(\mathrm{mg} / \mathrm{kg})$ & Recovery $(\%)$ \\
\hline $50 \mathrm{mg} / \mathrm{kg} \mathrm{Se}(\mathrm{VI})^{\mathrm{a}}$ & 50.0 & $49.2 \pm 2.7$ & 98.5 \\
$100 \mathrm{mg} / \mathrm{kg} \mathrm{Se}(\mathrm{Vl})^{\mathrm{b}}$ & 100.1 & $101.9 \pm 2.0$ & 101.8
\end{tabular}

${ }^{\mathrm{a}} 25 \mathrm{mg} / \mathrm{kg}$ Se (IV) $+25 \mathrm{mg} / \mathrm{kg}$ Se (VI) sample was prepared, and Se (IV) was oxidized to Se (VI)

${ }^{b} 50 \mathrm{mg} / \mathrm{kg}$ Se (IV) + $50 \mathrm{mg} / \mathrm{kg}$ Se (VI) sample was prepared, and Se (IV) was oxidized to Se (VI)

kinds of inorganic selenium species using this principle, the $\mathrm{pH}$ value of the sample should be 2 or less. It is not suitable for this method because of its strong acidity. The recommended $\mathrm{pH}$ value ranges from 2 to 12 for the ion exchange membrane. Thus, Se (IV) was oxidized to $\mathrm{Se}(\mathrm{VI})$ and quantified in the form of total inorganic selenium. The ionic characteristics of Se (VI) were highly depend on the $\mathrm{pH}$ of the solution. So, the recoveries of $\mathrm{Se}$ (VI) collected on extraction membrane filter disk were investigated with the different $\mathrm{pH}$ of solution. The $\mathrm{pH}$ of the calibration standard and sample was adjusted by the $28 \%$ ammonium hydroxide. The small amounts of the concentrated ammonium hydroxide were added to the sample solutions in which the concentrations of $\mathrm{Se}$ (VI) had been set to sample concentration. Four sample solutions were prepared with the same Se (VI) concentrations at different $\mathrm{pH}$ values, 3.0, 5.0, 7.0, and 9.0. Figure 2a shows the variation of LIBS signal intensities
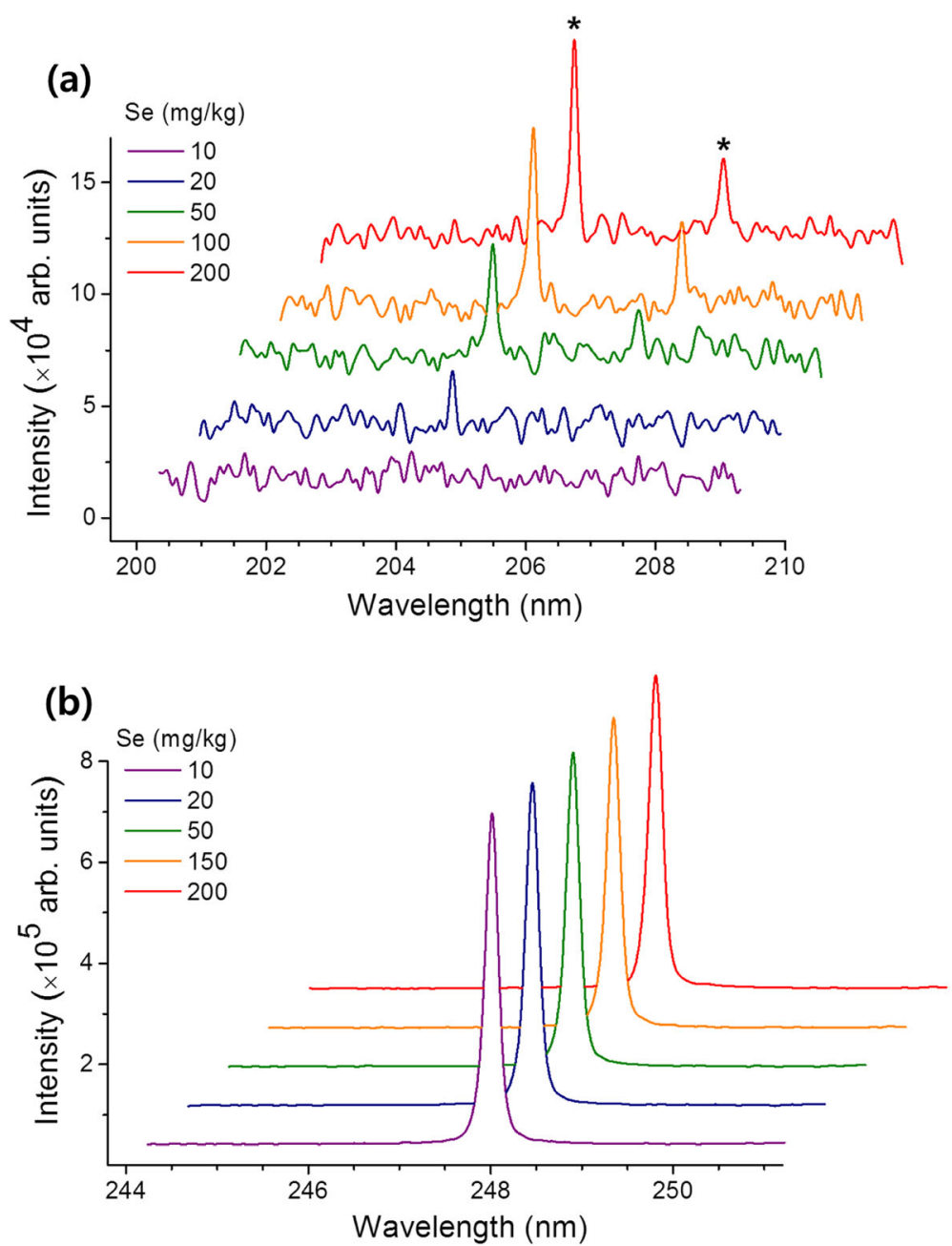

Fig. 3 LIBS spectra of the LIBS calibration standards with five different Se (VI) concentrations (10, 20, 50, 150, and $200 \mathrm{mg} / \mathrm{kg}$ ) in the wavelength regions where the $\mathbf{a}$ Se (I) and $\mathbf{b} C(I)$ emission lines were observed. In (a), the two peaks denoted by "** are the Se (I) emission lines at 203.99 and $206.28 \mathrm{~nm}$. The $C(\mathbf{I})$ lines at $247.86 \mathrm{~nm}$, shown in (b), originated from the membrane filter material 
of Se (VI) collected on the extraction membrane filter disk at the different $\mathrm{pH}$. The error bars represent standard deviations for the corresponding five repetitive measurements. The signal intensity was the highest at $\mathrm{pH} 7$. In the case of $\mathrm{pH} 3,5$, and 9, the signal intensity was lower than that measured at $\mathrm{pH} 7$; so, Se (VI) could not be recovered in its entirety.

In addition, the flow rate of sample influenced the recovery. Thus, the results were analyzed by adjusting the four different flow rates: $1,2,4$, and $8 \mathrm{~mL} / \mathrm{min}$. Figure $2 \mathrm{~b}$ shows the signal intensities at different flow rates. The error bars represent standard deviations for the corresponding five repetitive measurements. The flow rates were changed from 1 to $8 \mathrm{~mL} / \mathrm{min}$ for optimization, and the signal intensity was the highest at $2 \mathrm{~mL} / \mathrm{min}$. Since the signal intensity at different flow rates $(1,4$, and $8 \mathrm{~mL} / \mathrm{min})$ is lower than the signal intensity at the flow rate $2 \mathrm{~mL} / \mathrm{min}$, it can also be assumed that not all of Se (VI) has been recovered.

\section{Determination of Se (VI)}

Standard solutions for the determination of Se (VI) were prepared. A Se (IV) and Se (VI) standard was oxidized to Se (VI) before passed through the extraction membrane filter disk, and the anionic Se (VI) remained on the disk was measured by LIBS. Table 1 shows the recovery of Se (VI). The recoveries of $50 \mathrm{mg} / \mathrm{kg}$ and 100 $\mathrm{mg} / \mathrm{kg}$ oxidized Se (VI) standard recovery were $98.5 \%$ and $101.8 \%$, respectively.

\section{Calibration curves and detection limits}

Five standard solutions were prepared with the $\mathrm{pH}$, 7.0. Each solution was flowed through a membrane filter. The dried membrane filter was analyzed by LIBS. Membrane filters containing the standard Se (VI) with the concentration range from 10 to $200 \mathrm{mg} /$ $\mathrm{kg}$ were prepared for LIBS calibration. Emission was collected for 200 laser shots per spectrum. The spectra in the wavelength regions, where the Se (I) and C (I) emission lines were observed, are shown in Fig. 3. Two Se (I) emission lines at 203.99 and $206.28 \mathrm{~nm}$, indicated by “" in Fig. 3a, were assigned based on the NIST Atomic Spectra Database. The intensities of these Se (I) lines show clear positive correlations with the concentration of $\mathrm{Se}$ in the calibration standards. Among them, one of the strongest lines at $203.99 \mathrm{~nm}$ was chosen for developing the calibration curve. For the five calibration standards, the C (I) line at 247.86 $\mathrm{nm}$ was observed with very similar intensities. This $\mathrm{C}$ (I) emission originates from the ablation of the filter material. This indicates that our measurement condition is found to be quite consistent from sample to sample. Thus, any additional data processing of intensity normalization was not applied.

The analytical calibration curve for Se (VI) was shown in Fig. 4. The calibration curves of Se (VI) showed good linearity in the range of $10-200 \mathrm{mg} / \mathrm{kg}$. The measured Se (I) line intensities are fitted well with a linear function $\left(R^{2}=0.9983\right)$. The calibration curve shows linear dynamic ranges of 1-2 orders of magnitude for Se (VI).

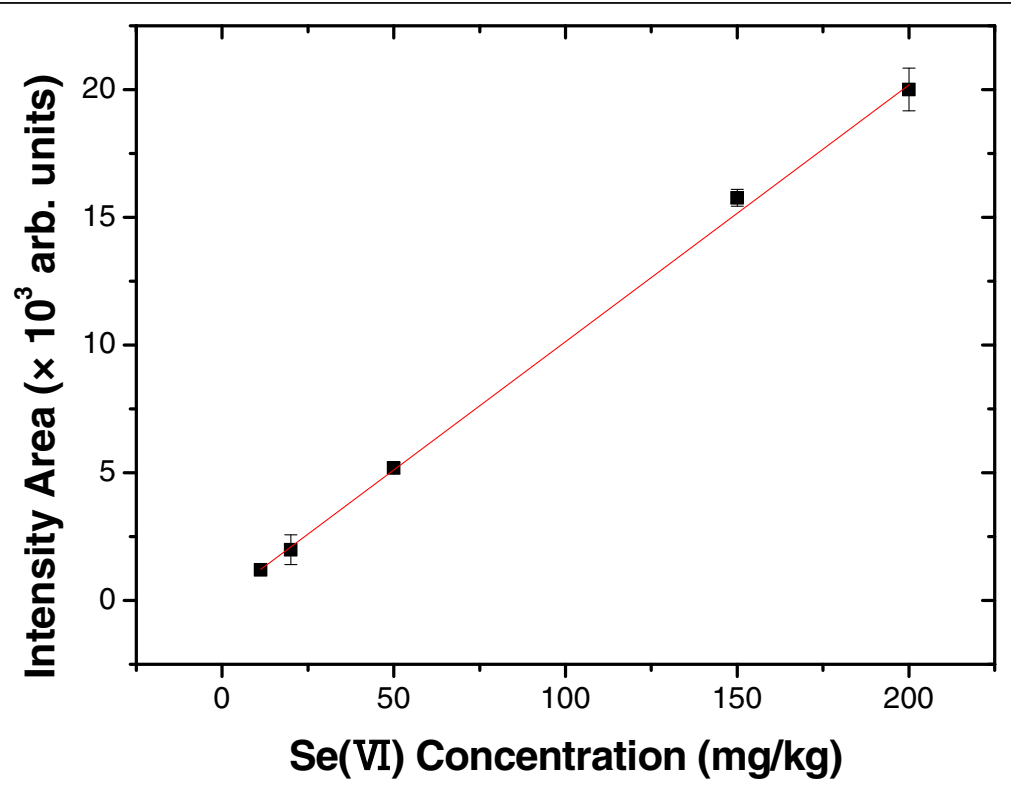

Fig. 4 Calibration curve of Se (VI) from LIBS analysis of the membrane filters. The filled squares represent the experimental values, and the red line is a linear fit of them $\left(y=a+b x\right.$, with $a=-6.85 \pm 5.05, b=10.55 \pm 0.06$, and $\left.R^{2}=0.9983\right)$ 
Table 2 Analysis of Se (VI) in sample with Se (VI) added to tap water

\begin{tabular}{llll}
\hline Sample & Concentration of Se $(\mathrm{Vl})$ in sample solution $(\mathrm{mg} / \mathrm{kg})$ & Result by LIBS $(\mathrm{mg} / \mathrm{kg})$ & Recovery $(\%)$ \\
\hline Tap water & - & N.D. $^{\text {a }}$ & - \\
Tap water spiked with Se $(\mathrm{Vl})$ & 50.01 & $50.7 \pm 2.0$ & 101.3
\end{tabular}

${ }^{\mathrm{a}}$ Not detected

The correlation coefficients ranged from 0.99 to 1.00 . The error bars represent two times of standard deviations. The limit of detection for Se (VI) was $11 \mathrm{mg} / \mathrm{kg}$. The detection limit was defined as the concentration giving a signal equivalent to three times the noise, calculated from the standard deviation of 3 repetitive measurement of the background intensities.

\section{Performances for spike water}

The procedure presented was applied to the detection of Se (VI) in natural water samples from a tap water from Muan County in Republic of Korea. As a result, Se (VI) was not detected. Thus, Se (VI) was spiked into the tap water. The concentration of the spiked Se $(\mathrm{VI})$ was determined to be $50.7 \pm 0.2 \mathrm{mg} / \mathrm{kg}$. This leads to the recovery efficiency of $101.3 \%$. The results are listed in Table 2 . The result described that the developed method can be applied to the real water samples such as rainwater and drinking water for the determination of inorganic selenium.

\section{Further improvement of LOD}

For reliable analysis of selenium in natural water or blood samples, the ppb-level LOD is required. Our current method provides the lower LOD $(11 \mathrm{mg} / \mathrm{kg})$. However, it can be improved further. It should be noted that the current LOD can be lowered much even retaining the current experimental setup. We investigated variation of the signal-to-noise ratio with the laser scan number. Each laser scan was performed accumulating 200 laser shots. Nine line scans were conducted consecutively. Then, nine spectra were produced by averaging different numbers of line scans from one to nine. Then, for each spectrum, the signal intensity was obtained by taking area under the baseline-subtracted Se emission peak at $203.93 \mathrm{~nm}$. The noise was estimated by the root-mean-square-error of the baseline intensities in the wavelength region between $200.634 \mathrm{~nm}$ and 207.159 $\mathrm{nm}$. To obtain the noise, the intensities around the Se emission peak were excluded (203.806-204.070 nm). In Fig. 5, the signal-to-noise ratio values were plotted with respect to the corresponding numbers of line scans averaged. The LOD of $11 \mathrm{mg} / \mathrm{kg}$ was estimated using three

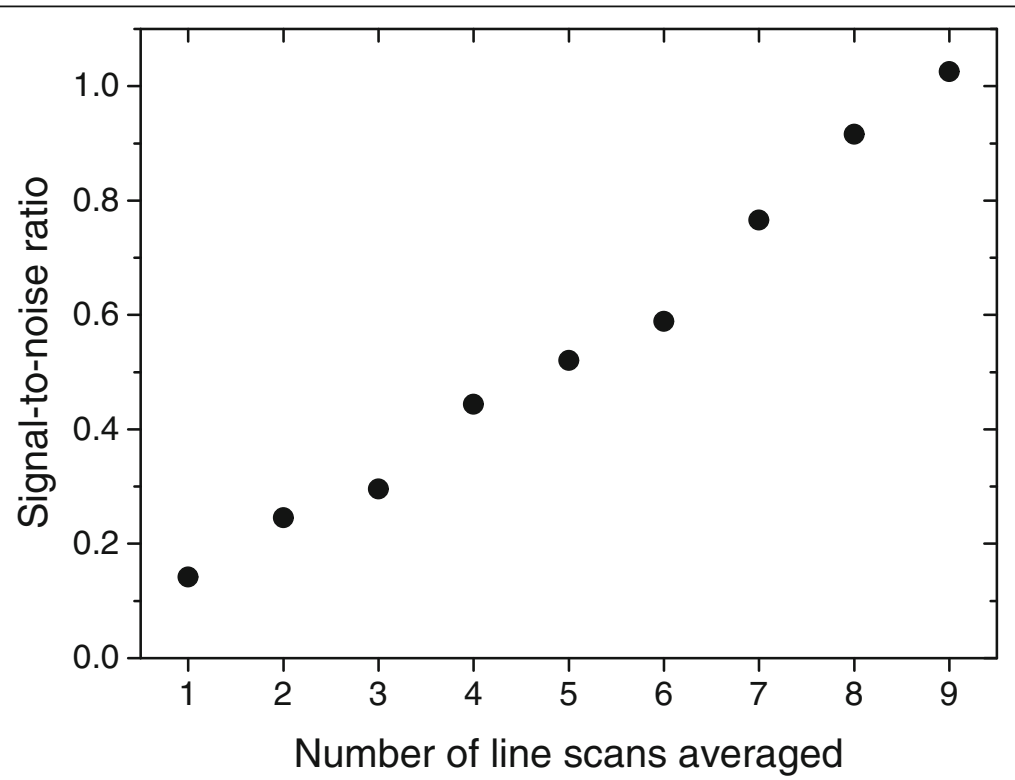

Fig. 5 Signal-to-noise ratio values with respect to the corresponding numbers of line scans averaged. The signal intensities were taken for the Se emission peak at $203.93 \mathrm{~nm}$, and the noise values were estimated from the baseline intensities nearby the Se emission peak (see text) 
line scans. The corresponding signal-to-noise ratio is 0.30 . If the number of line scans were increased from 3 to 9 , the signal-to-noise ratio is increased to 1.03 by a factor of 3.4. It leads the LOD of $3.2 \mathrm{mg} / \mathrm{kg}$. As can be seen in Fig. 5, the signal-to-noise ratio seems to increase further for the larger numbers of line scans averaged than 9. In addition, the ion exchange membrane was kept unsaturated in this experiment, so it has unused binding capacity for further pre-concentration of Se. From the calibration curve shown in Fig. 4, it can be found that the ion exchange membrane has not been saturated by $10 \mathrm{~mL}$ of the most concentrated Se standard solution $(200 \mathrm{mg} / \mathrm{kg})$. This implies that the current LOD performance can be improved further at least by a factor of $18(=200 / 11)$. Averaging more line-scan data and increasing the volume of solution, the LOD of 100$200 \mu \mathrm{g} / \mathrm{kg}$ might be obtained. However, the lower ppblevel analysis requires the higher-performance detection systems such as ICP-MS. The ICP-MS can be used in combination with laser-ablation sampling which was used for this LIBS analysis. Currently, the research for application of our simple selenium speciation method and the laser-ablation sampling to ICP-MS analysis is in progress.

\section{Conclusion}

We demonstrated a simple methodology for quantification of inorganic selenium in water. The ion exchange membrane was employed for selectively collecting Se (VI) species in watery. Se (IV) was oxidized to Se (VI) and adsorbed on the membrane in the form of inorganic selenium and analyzed by LIBS. LIBS analysis for the membrane holding Se (VI) species showed reliable analytical performances: measurement precision of a few percent relative standard deviation, limit of detection of $11 \mathrm{mg}$ Se out of $1 \mathrm{~kg}$ of water, and linear dynamic range from 10 to $200 \mathrm{mg} / \mathrm{kg}$.

It is possible to analyze inorganic selenium by ion exchange membrane filter and LIBS. The analytical method can be faster and simpler than conventional methods. To apply our methodology to real samples such as rainwater and drinking water, further improvement in the LOD performance is definitely necessary and currently in progress.

\footnotetext{
Abbreviations

HG-AAS: Hydride generation-atomic absorption spectroscopy; HPLC-ICPMS: High performance liquid chromatography-inductively coupled plasmamass spectrometry; GC-MS: Gas chromatography-mass spectroscopy; IC-ICPMS: Ion chromatography-inductively coupled plasma-mass spectrometry; SPE: Solid-phase extraction; LIBS: Laser-induced breakdown spectroscopy; ND:YAG: Neodymium-doped yttrium aluminum garnet; CCD: Charge-coupled device
}

\section{Acknowledgements}

This work was supported by the Basic Science Research Program through the National Research Foundation of Korea (NRF), funded by the Ministry of
Science, ICT, and Future Planning (grant Number 2019R1A2C1003069), and the Korea Basic Science Institute(KBSI) National Research Facilities \& Equipment Center(NFEC) grant funded by the Korea government (Ministry of Education) (grant Number. 2019R1A6C1010005).

\section{Authors' contributions}

SHN designed the study and directed all experiments. YL advised on LIBS support and measurement. The experiment was executed by SHL and SWK All authors read and approved the final manuscript.

Funding

No applicable.

Availability of data and materials

All data generated and analyzed in this study have been provided in the manuscript.

\section{Competing interests}

The authors declare that they have no competing interests.

Received: 28 April 2020 Accepted: 30 June 2020

Published online: 07 July 2020

\section{References}

Alissa EM, Bahijri SM, Ferns GA. The controversy surrounding selenium and cardiovascular disease: a review of the evidence. Med Sci Monit. 2003;9:9-18.

Brown K, Arthur J. Selenium, selenoproteins and human health: a review. Public Health Nutr. 2001:4:593-9.

Dockery CR, Pender JE, Goode SR. Speciation of chromium via laser-induced breakdown spectroscopy of ion exchange polymer membranes. Appl Spectrosc. 2005;59:252-7.

Dumont E, Vanhaecke F, Cornelis R. Selenium speciation from food source to metabolites: a critical review. Anal Bioanal Chem. 2006;385:1304-23.

Finley JW. Selenium accumulation in plant foods. Nutr Rev. 2005;63:196-202.

Fio JL, Fujii R. Selenium speciation methods and application to soil saturation extracts from San Joaquin Valley, California. Soil Sci Soc Am J. 1990;54:363-9.

Foster LH, Sumar S. Selenium in health and disease: a review. Crit Rev Food Sci Nutr. 1997;37:211-28.

Garousi F. The toxicity of different selenium forms and compounds - review. Acta Agrar Debreceniensis. 2015;64:33-8.

Li HF, Lombi E, Stroud JL, McGrath SP, Zhao FJ. Selenium speciation in soil and rice: influence of water management and Se fertilization. J Agric Food Chem. 2010;58:11837-43.

Lobinski R, Edmonds JS, Suzuki KT, Uden PC. Species-selective determination of selenium compounds in biological materials. Pure Appl Chem. 2000;72:447-61.

Mahima, Verma AK, Kumar A, Rahal A, Kumar V, Roy D. Inorganic versus organic selenium supplementation: a review. Pakistan J Biol Sci. 2012;15:418-25.

Martínez-Bravo Y, Roig-Navarro AF, López FJ, Hernández F. Multielemental determination of arsenic, selenium and chromium(VI) species in water by high-performance liquid chromatography-inductively coupled plasma mass spectrometry. J Chromatogr A. 2001;926:265-74.

Michalke B. Element speciation definitions, analytical methodology, and some examples. Ecotoxicol Environ Saf. 2003;56:122-39.

Nam SH, Kwon SW, Lee Y. Feasibility of separation and quantification of inorganic arsenic species using ion-exchange membranes and laser-induced breakdown spectroscopy. Anal Lett. 2018;15:2833-46.

Navarro-Alarcón M, López-Martínez MC. Essentiality of selenium in the human body: relationship with different diseases. Sci Total Environ. 2000;249:347-71.

Peng $\mathrm{H}$, Zhang N, He M, Chen B, Hu B. Simultaneous speciation analysis of inorganic arsenic, chromium and selenium in environmental waters by 3-(2aminoethylamino) propyltrimethoxysilane modified multi-wall carbon nanotubes packed microcolumn solid phase extraction and ICP-MS. Talanta. 2015;131:266-72

Roberge MT, Borgerding AJ, Finley JW. Speciation of selenium compounds from high selenium broccoli is affected by the extracting solution. J Agric Food Chem. 2003;51:4191-7.

Rohn I, Marschall TA, Kroepfl N, Jensen KB, Aschner M, Tuck S, Kuehnelt D, Schwerdtle T, Bornhorst J. Selenium species-dependent toxicity, bioavailability andmetabolic transformations in Caenorhabditis elegans. Metallomics. 2018;10:818-27. 
Sandholm M, Okanen HE, Pesonen L. Uptake of selenium by aquatic organisms. Limnol Oceanogr. 1973;18:496-9.

Selinus O. Essentials of Medical Geology. revised ed. Heidelberg: Springer Science \& Business Media; 2013

Suzuki KT, Itoh M, Ohmichi M. Selenium distribution and metabolic profile in relation to nutritional selenium status in rats. Toxicology. 1995;103:157-65.

Thomson CD. Selenium and iodine intakes and status in New Zealand and Australia. Br J Nutr. 2004;91:661.

WHO. Trace elements in human nutrition and health. Report of a WHO Expert Committee. Geneva: World Heal. Organ; 1996.

Wu D, Sun S. Speciation analysis of As, Sb and Se. Trends Environ Anal Chem. 2016;11:9-22.

Xiong Y, Li F, Wang J, Huang A, Wu M, Zhang Z, Zhu D, Xie W, Duan Z, Su L. Simple multimodal detection of selenium in water and vegetable samples by a catalytic chromogenic method. Anal Methods. 2018;10:2102-7.

\section{Publisher's Note}

Springer Nature remains neutral with regard to jurisdictional claims in published maps and institutional affiliations.

\section{Submit your manuscript to a SpringerOpen ${ }^{\circ}$ journal and benefit from:}

- Convenient online submission

- Rigorous peer review

- Open access: articles freely available online

- High visibility within the field

- Retaining the copyright to your article

Submit your next manuscript at $\boldsymbol{\nabla}$ springeropen.com 